\title{
Ongoing outbreak of hepatitis A in Italy: preliminary report as of 31 May 2013
}

C Rizzo (caterina.rizzo@iss.it) ${ }^{1}$, V Alfonsi ${ }^{1}$, R Bruni ${ }^{2}$, L Busani ${ }^{3}$, A R Ciccaglione ${ }^{2}$, D De Medici C S Di Pasquale $^{3}$, M Equestre $^{2}$, M Escher, M C Montaño-Remacha ${ }^{1,4}$, G Scavia ${ }^{3}$, S Taffon $^{2}$, V Carraro ${ }^{5}$, S Franchini ${ }^{5}$, B Natter ${ }^{6}$, M Augschiller ${ }^{6}$, M E Tosti ${ }^{1}$, the Central Task Force on Hepatitis A $^{7}$

1. Istituto Superiore di Sanità (ISS), National Centre for Epidemiology Surveillance and Health Promotion, Rome, Italy

2. Istituto Superiore di Sanità (ISS), Department of Infectious, Parasitic and Immune-mediated Diseases

3. Istituto Superiore di Sanità (ISS), Department of Veterinary Public Health and Food Safety

4. European Programme for Intervention Epidemiology Training (EPIET), European Centre for Disease Prevention and Control (ECDC), Stockholm, Sweden

5. Department of Health, Province of Trento, Italy

6. Department of Health, Province of Bolzano, Italy

7. The members of the Central Task Force on Hepatitis A are listed at the end of the article

Citation style for this article:
Rizzo C, Alfonsi V, Bruni R, Busani L, Ciccaglione AR, De Medici D, Di Pasquale S, Equestre M, Escher M, Montaño-Remacha MC, Scavia G, Taffon S, Carraro V,

Franchini S, Natter B, Augschiller M, Tosti ME, the Central Task Force on Hepatitis A. Ongoing outbreak of hepatitis A in Italy: preliminary report as of 31 May 2013. Euro Surveill. 2013;18(27):pii=20518. Available online: http://www.eurosurveillance.org/ViewArticle.aspx?Articleld=20518

Since January 2013, an unusual increase in hepatitis A cases has been detected in northern Italy. A total number of 352 cases were reported to the integrated surveillance system between January and the end of May 2013 and this represents a 70\% increase compared to the same period of the previous year. The outbreak is ongoing and the public health authorities are continuing their investigations to establish the transmission vehicle and to control the outbreak.

From 1 January 2013 to 31 May 2013 a total of 352 cases of hepatitis A were reported to the Italian national surveillance system, corresponding to a $70 \%, 54 \%$, and $34 \%$ increase in HAV notifications compared to the same period in 2012, 2011 and 2010, respectively. Here we describe the epidemiological features of the cases and the investigation of the outbreak.

\section{Surveillance of hepatitis A in Italy}

Hepatitis $A$ is a notifiable disease in Italy. According to the national legislation, laboratory-confirmed cases of hepatitis $A$ virus (HAV) infection are reported by clinicians to the local health units (LHUs) which are responsible for the epidemiological investigation. From the LHUs, notifications are sent to the regional health authorities (RHAs) and from here to the Ministry of Health. However, the routine notification system does not collect information on risk groups and risk factors associated with hepatitis $A$ and there is an important delay in the transmission of the data [1]. For this reason, in 1984, a specific sentinel surveillance system for acute viral hepatitis (SEIEVA -Sistema Epidemiologico Integrato Epatiti Virali Acute) was set up in parallel with the official notification system in Italy [2]. Data included in the SEIEVA system provide insight into the risk factors associated with the disease. Data collected by SEIEVA are provided by LHUs, which participate on a voluntary basis. A case is defined as a person with an acute illness including symptoms clinically compatible with hepatitis A, such as fever, fatigue, nausea, vomiting, abdominal pain, dark urine and jaundice, and positive for IgM anti-HAV. Cases are interviewed using a standardised online questionnaire collecting socio-demographic, clinical and laboratory information, and information on possible risk factors (shellfish consumption, contact with a jaundice case, travel to an endemic area, child attending daycare in the household, intravenous drug use in the last six months). After the alert issued by the northern European countries about a possible association between the hepatitis A cases and frozen berries [3], the consumption of mixed frozen berries was included as another possible risk factor in the SEIEVA questionnaire at the end of April 2013.

As of 31 May 2013, 76\% of the Italian LHUs (139/181) participate in the SEIEVA. The participating LHUs are distributed all over the country and cover $70 \%$ of the population. Data were adjusted considering the total population of the LHUs' catchment areas.

\section{Epidemiological situation of hepatitis A in Italy}

In recent decades, the epidemiological pattern of hepatitis A has changed. Italy is considered to be at low/ intermediate endemicity for HAV $[2,4]$. The improved health and sanitary conditions have favored a progressive decrease of the infection rate in children, and a major shift of the population at risk, with the highest incidence reported in young adults. Outbreaks were described in 1996-1997 and 2004 mainly in southern Italian regions (Apulia and Campania) and were related to the consumption of contaminated raw shellfish $[5,6]$. From 1997, when the incidence was 19 per 100,000 


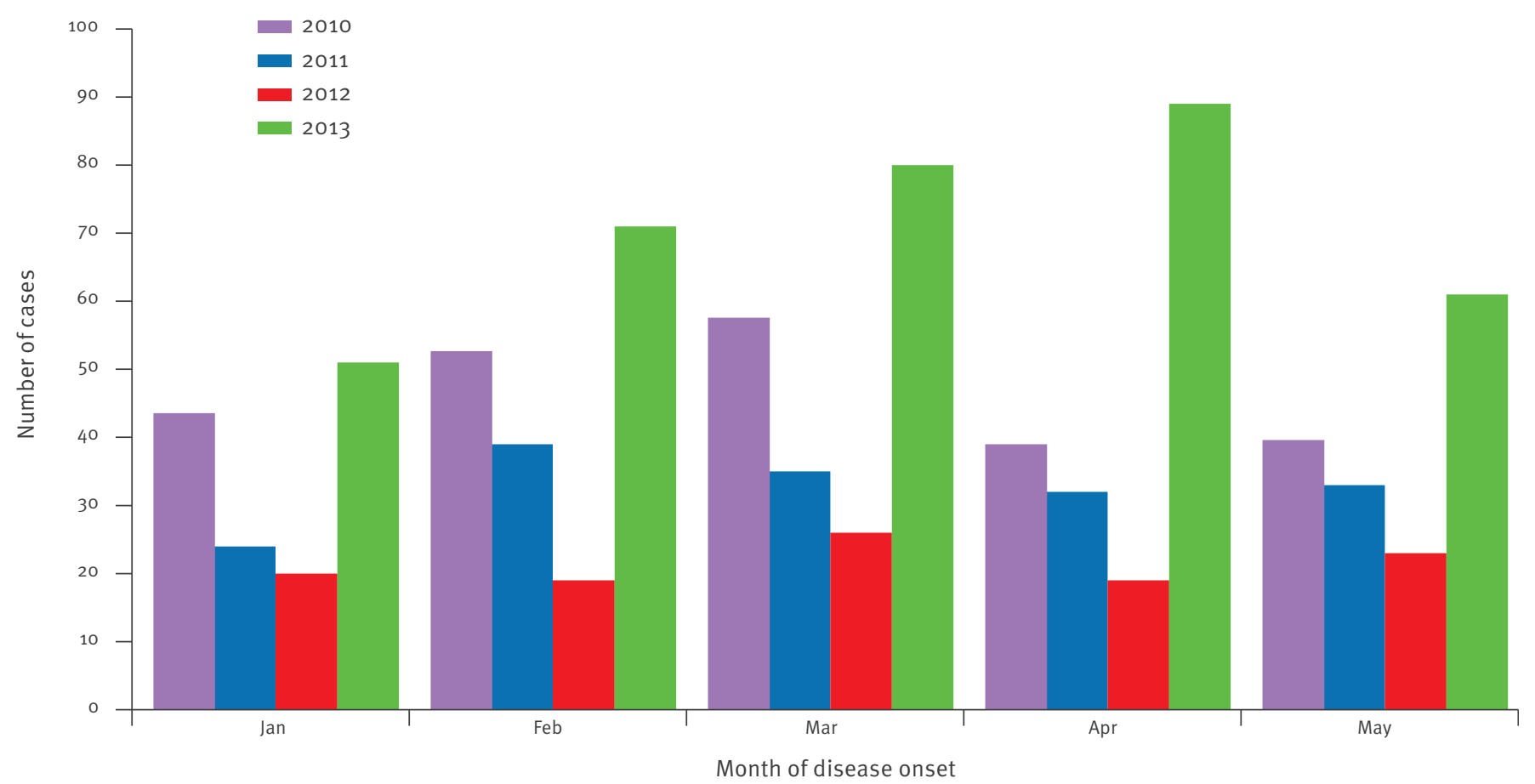

Source: Sentinel surveillance system for acute viral hepatitis (Sistema Epidemiologico Integrato Epatiti Virali Acute - SEIEVA)

population [2] to date, a decreasing trend in the incidence of HAV has been observed, to 1.1 cases, 0.7 and 0.8 per 100,000 population in 2010, 2011, and 2012, respectively [7].

\section{The 2013 hepatitis A outbreak in Italy}

From 1 January 2013 to 31 May 2013 a total number of 352 cases of hepatitis A were reported to SEIEVA surveillance system, corresponding to a 70\%, 54\% and $34 \%$ increase in HAV notifications compared to the same period in 2012, 2011 and 2010, respectively (Figure 1).

The highest increase in the number of cases was observed in seven northern Italian regions (Trento and Bolzano, Emilia-Romagna, Lombardy, Friuli Venezia Giulia, Piedmont, and Veneto) that accounted for $193 / 352$ (55\%) of the total cases recorded in 2013 . In these seven regions, the cumulative incidence was 2.66 per 100,000 population in the five-month reference period. Another region that showed an increase in the number of cases in 2013 is Apulia, in southern Italy, which recorded a $22 \%$ increase in the number of cases in 2013; 77 of the 352 cases were reported from this region.
The distribution of cases by age group and year is reported in Figure 2. The mean age of cases was 35 years (range: 2-63 years) and the median was 39 years; 23 cases $(12 \%)$ were recorded in children under 14 years. The cases were equally distributed among men and women: $55 \%$ of the cases were men and $45 \%$ were women. A total of 159 persons were hospitalised, with the majority of hospitalised cases in the age group of 35-54 years. As of 31 May 2013, no acute liver failures and deaths occurred. Four cases had been vaccinated against hepatitis $A$, with one dose within the three weeks before the onset of symptoms, so these were not considered vaccine failures.

With regard to the risk factors, among those who answered the questionnaire (193 cases), 3\% (7/193) reported to have travelled to Egypt, 17\% (33/193) reported to have eaten raw seafood and 20\% (37/193) mixed berries in the six weeks before the symptom onset. When considering risk factors distribution after the end of April (date of introduction of the question on the consumption of frozen mixed berries), the majority of cases (37 of 46 ) reported having consumed frozen mixed berries. 
Description of the 2013 hepatitis

\section{A outbreak in the provinces}

of Trento and Bolzano

In May 2013, Germany, the Netherlands and Poland reported trough the Epidemic Intelligence Information System for food- and waterborne diseases (EPIS-FWD) and the Early Warning and Response System (EWRS) 15 cases of HAV infection associated with a ski holiday in the autonomous provinces of Trento and Bolzano (northern Italy). The sequencing of the VP1-region of these five Italian isolates, from Trento province, showed $100 \%$ nucleotides homology with those isolated from two German and one Dutch case [8].

After the EPIS and EWRS notifications, a retrospective epidemiological investigation started in the provinces of Trento and Bolzano, contacting cases notified through the regional notification system. For the epidemiological investigation, a confirmed case was defined as a person resident in the provinces of Trento and Bolzano with an acute illness including symptoms clinically compatible with hepatitis A, such as fever, fatigue, nausea, vomiting, abdominal pain, dark urine and jaundice, and identified as positive for IgM antiHAV after 1 January 2013.

Between 1 January and 31 May 2013, 31 cases of HAV infection were notified in the province of Trento (a 13-fold, 19-fold and 6-fold increase approximately, compared to the same period in 2012, 2011, and, 2010 respectively). The first case reported the onset of symptoms on 2 February and the most recent case was identified on 31 May. Most of the cases had the onset of symptoms in May (15 cases).

In the province of Bolzano, seven cases were reported in the same period. The epidemic curve of the 38 confirmed HAV infection cases in these two provinces shows the evolution of the outbreak over time and suggests a common vehicle of transmission (Figure 3).

In these two provinces, the mean age of the cases was 36.3 years (range: $3-63$ years) and the median was 38.5 years. Men were more represented than women (24 versus 14). A total of 31 persons were hospitalised and the majority of them were 35 to 54 years-old. There was only one case vaccinated and this case was reported

\section{FIGURE 2}

Distribution of hepatitis A cases by age group in seven Italian regions ${ }^{\text {a }}$ January-May 2010 to January-May 2013

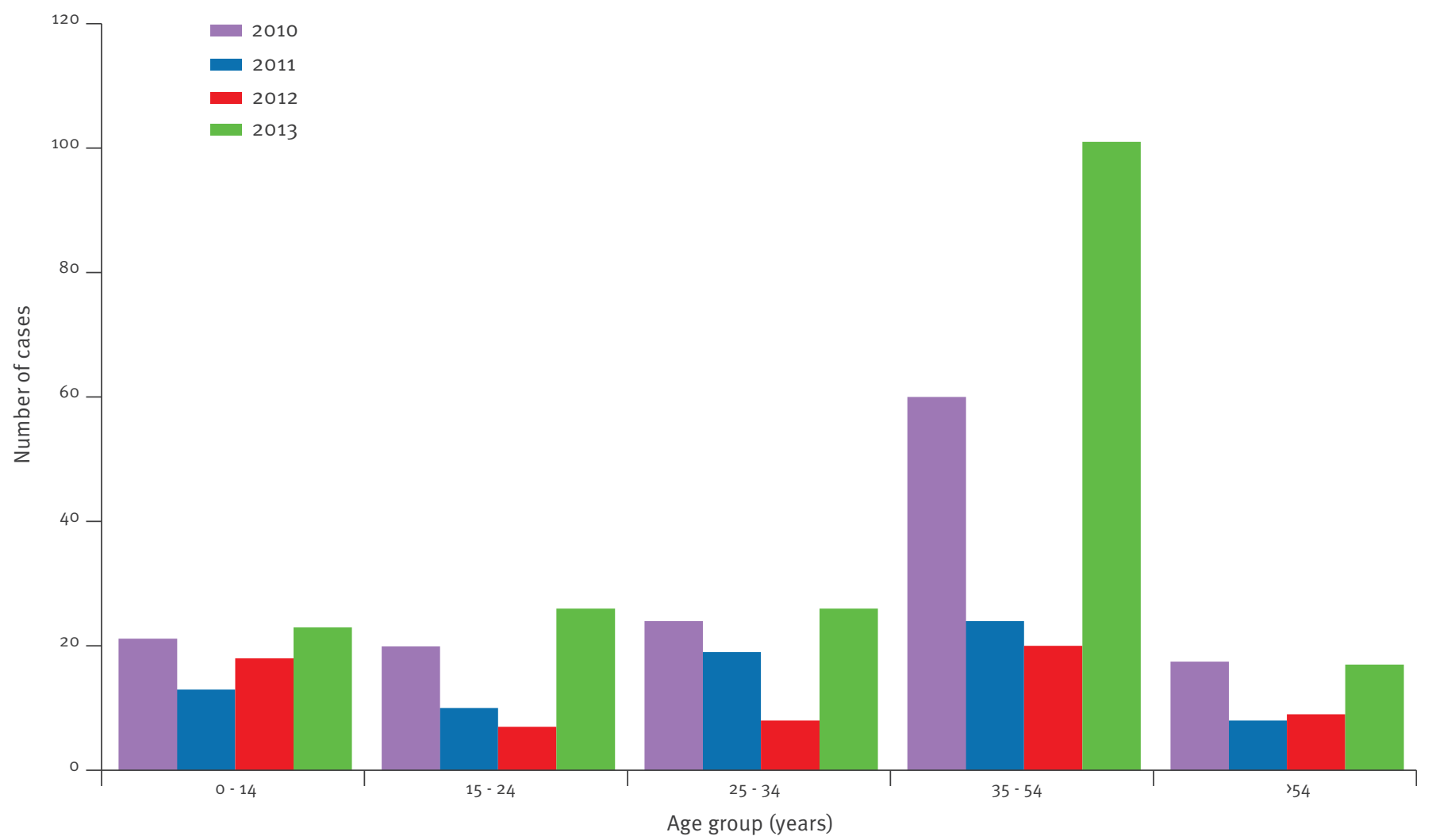

a Trento and Bolzano, Emilia-Romagna, Lombardy, Friuli Venezia Giulia, Piedmont, and Veneto. 
Hepatitis A cases by week of symptom onset, provinces of Trento and Bolzano, Italy, January-May $2013(\mathrm{n}=38)$

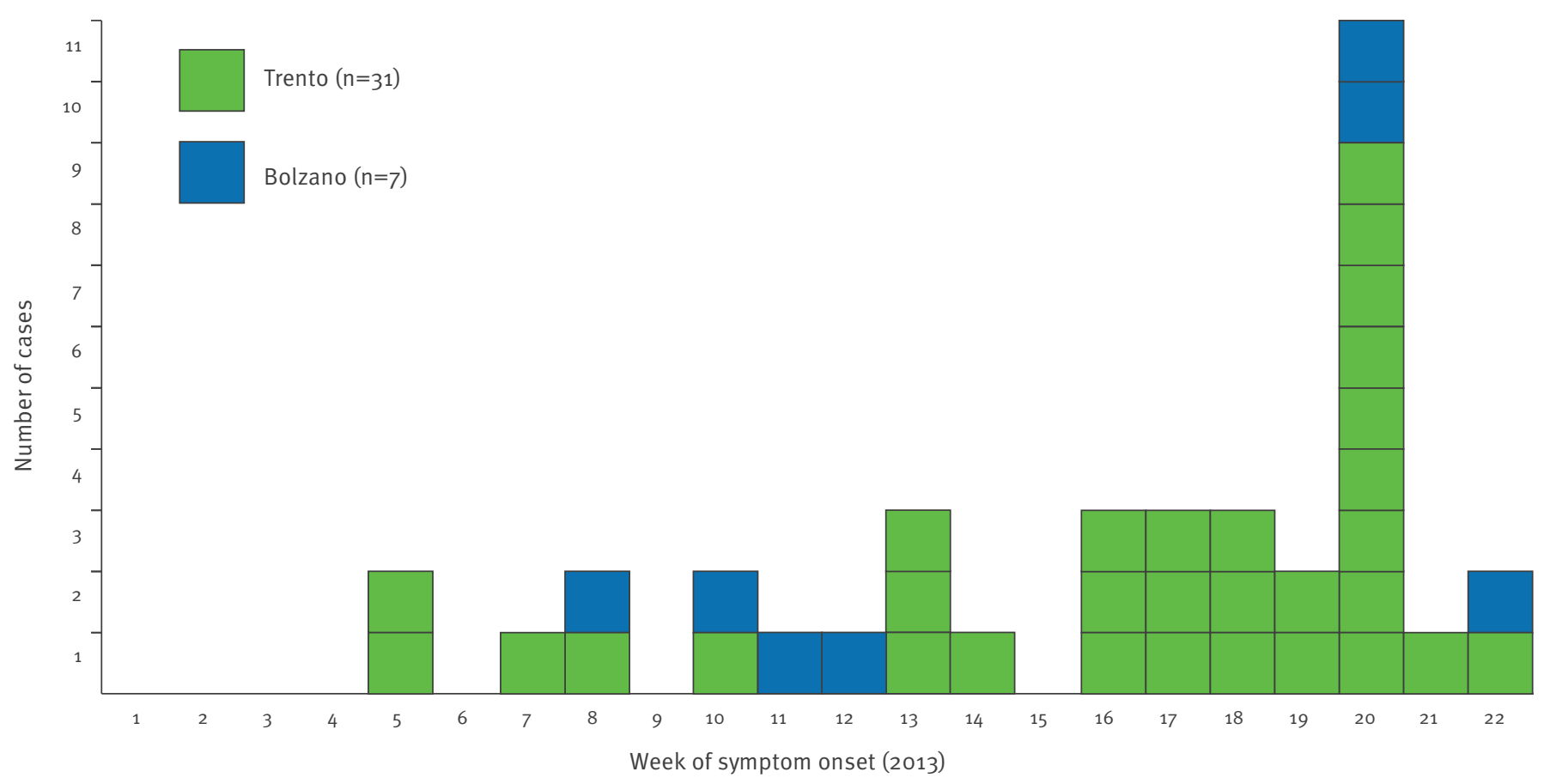

Source: Sentinel surveillance system for acute viral hepatitis (Sistema Epidemiologico Integrato Epatiti Virali Acute - SEIEVA)

from the province of Trento; however, this case had been vaccinated with one dose within the three weeks before the onset of symptoms, so this was not considered a vaccine failure. Preliminary epidemiological investigation for the identification of risk factors and common exposures focused on consumption of contaminated food as no epidemiological link between the cases could be confirmed. The only common food consumed by all cases was mixed berries or food containing mixed berries (cakes).

Serum samples were collected during the acute phase of the disease from five of the 38 cases, all from the Trento province. The sequence of the $\mathrm{VP}_{1} / 2 \mathrm{~A}$ region of the HAV $1 \mathrm{~A}$ virus obtained from all of them (with GenBank accession number KF182323) showed a 100\% nucleotides homology with sequences of the isolates from the German and Dutch cases.

\section{Investigation of food items implicated}

The preliminary epidemiological investigation in the provinces of Trento and Bolzano showed that the only common food consumed by different cases was mixed berries or food containing mixed berries (cakes). Moreover, the hypothesis was strongly supported by the results of an epidemiological investigation conducted in a family cluster in Veneto region. Part of the mixed berries (redcurrant, blackberries, raspberries, blueberries) that the cases indicated to have eaten within the period of time compatible with the onset of clinical symptoms were still available and were sampled. The analysis for HAV detection in the sample of mixed berries provided positive results. As a consequence, on 17 May, the Italian Ministry of Health (which is the food safety authority at national level) communicated these findings through the European Rapid Alert System for Food and Feed (RASFF). Following these preliminary positive results, the surveillance of these food items was intensified. More samples of berries were collected throughout the country once they were identified as potential risk factors, and two sampled berries in Trento were found positive for HAV. On 30 May, two additional RASFF notifications were issued to inform about new HAV findings in frozen mixed berries from Italy. Environmental investigations have been done on the mixed frozen berries suppliers of raw material in six different countries. Results on samples collected are pending at the time of the present rapid communication.

\section{Control measures}

On 23 May the Ministry of Health (the General Direction for Prevention together with the food safety authority) published a note for RHAs in order to enhance surveillance and awareness of HAV recommending to report within 24 hours any new HAV cases, to collect 
additional epidemiological information on risk factors associated, and perform virus genotyping and sequencing from all new cases. In addition to the recommendation mentioned above, a case-control study in the regions that experienced the highest increase of cases was planned, in order to support the hypothesis of berries as source of infection, to find other potential risk factors and to identify appropriate control measures. The National Institute of Health (Istituto Superiore di Sanità, ISS) is responsible of the coordination of the virological and epidemiological investigations, and of the case-control study.

Moreover, after the positive results on the sampled frozen mixed berries from different regions, the Ministry of Health started the tracing back this food item. The investigation identified a dealer that received consignments of berries from different countries (mix made in Italy, with raw material from Bulgaria, Canada, Poland, and Serbia).

Following the RASFF notification from the Ministry of Health, regions recalled the lots that were identified positive for HAV and advised the population through the website of the Ministry of Health regarding the use of the leftover frozen mixed berries. Trace back investigations on food are ongoing for each new case notified.

The European Centre for Disease Prevention and Control (ECDC) performed a rapid risk assessment that was published on 16 April 2013 [8].

\section{Discussion}

Preliminary analysis of the case interviews on possible risk factors associated with the ongoing outbreak identified consumption of frozen mixed berries (redcurrant, blackberries, raspberries, blueberries) as potential vehicle of infection. The hypothesis that they could be implicated is strongly supported by the detection of HAV virus in a sample of frozen mixed berries. The surveillance on these frozen mixed berries together with other food items potentially carrying the HAV (vegetables, seafood, and other food reported as potential risk factors by cases in the epidemiological investigation), has been intensified, to provide a clear picture of the distribution of the contaminated items and the risk of exposure through these.

The case-control study is currently ongoing; the results of this investigation will provide an opportunity to support the hypothesis of the likely source of infection and together with the molecular sequencing information will provide a picture of the genotypes in this outbreak to be compared to those circulating in the previous years in Italy and to those that are currently circulating in other countries [9-12].

Comparison of information from the tracing-back of positive frozen mixed berries with information obtained through the purchase history is ongoing.
Seven sequences of HAV genotype $1 \mathrm{~A}$ isolated from cases in different countries (the Netherlands, Germany and Italy) and in different laboratories showed a $100 \%$ similarity. The genotype and the sequence of the virus isolated in the Italian outbreak is different from the currently ongoing outbreak with frozen berries as suspected vehicle described in northern European countries and in the United States $[3,12,13]$.

Despite the great efforts made in the detection of positive food consignments and recall of those suspected or found positive, more cases are expected in the next weeks, due to the long incubation period of HAV (2830 days; range: $15-50$ days) [14], the notification delay, and the long shelf life that frozen berries have.

The Italian public health authorities are collaborating closely in order to confirm the source of the outbreak and to stop further transmission.

The Central Task Force on Hepatitis A:

C Rizzo, V Alfonsi, R Bruni, L Busani, A Ciccaglione, D de Medici, S Di Pasquale, M Escher, M C Montaño-Remacha, G Scavia, M E Tosti (Istituto Superiore di Sanità), MG Pompa, V Martini, (Ministry of Health, DG for Prevention, V Office) MN Losio, G Varisco, E Pavoni (National Reference Centre for Emerging Risks in Food Safety, Istituto Zooprofilattico Sperimentale di Lombardia e Emilia Romagna), M Massaro, B Cappelletti, P Noè, A Menghi, S Guizzardi, G Plutino, D Monteleone, S Borrello (Ministry of Health, DG for Hygiene, Food Safety and Nutrition).

\section{Acknowledgements}

We are grateful to all colleagues from the regional and Local Health Authorities who provide data to the SEIEVA surveillance system.

Conflict of interest

None declared.

Authors' contributions

CR contributed to the descriptive study and drafted the manuscript as the lead writer. MET contributed with data on Italian cases. VA and MCMR gathered data from the different regions implicated and to the descriptive study. DDM, LB, ME, SDP, GS, contributed to describe the investigation on food items implicated and commented on the manuscript. $A C, R B, M E, S T$ contributed to the laboratory sequencing and analysis and commented on the manuscript. VC and SF contributed with data on Trento province cases. BN and MA contributed with data on Bolzano province cases. 


\section{References}

1. Carrieri MP, Salmaso S, Bella A, D’Ancona F, Demicheli $\mathrm{V}$, Marongiu C, et al. Evaluation of the SIMI system, an experimental computerised network for the surveillance of communicable diseases in Italy. Eur J Epidemiol. 2000;16(10):941-7.

http://dx.doi.org/10.1023/A:1011094116944 PMid:11338126

2. Mele A, Tosti ME, Spada E, Mariano A, Bianco E, SEIEVA collaborative group. Epidemiology of acute viral hepatitis: twenty years of surveillance through SEIEVA in Italy and a review of the literature. Rome: Istituto Superiore di Sanità; 2006. Report no 12. Available from: http://www.iss.it/binary/ publ/cont/06-12.1149070762.pdf

3. European Centre for Disease Prevention and Control (ECDC), European Food Safety Authority (EFSA). Joint ECDC-EFSA rapid outbreak assessment. Outbreak of hepatitis A virus infection in four Nordic countries. Stockholm: ECDC. 15 Apr 2013. Available from: http://www.ecdc.europa.eu/en/publications/ Publications/hepatitis-a-rapid-assessment-nordic-countriesapril2013.pdf

4. Stroffolini T, Mele A, Sagliocca L. Vaccination policy against hepatitis A in Italy. Vaccine. 2001;19(17-19):2404-6. http://dx.doi.org/10.1016/S0264-410X(oo)00463-1

5. Lopalco PL, Malfait P, Menniti-Ippolito F, Prato R, Germinario C, Chironna M, et al. Determinants of acquiring hepatitis A virus disease in a large Italian region in endemic and epidemic periods. J Viral Hepat. 2005;12(3):315-21. http://dx.doi. org/10.1111/j.1365-2893.2005.00593.x PMid:15850473

6. Pontrelli G, Boccia D, DI Renzi M, Massari M, Giugliano F, Celentano LP, et al. Epidemiological and virological characterization of a large community-wide outbreak of hepatitis A in southern Italy. Epidemiol Infect. 2008;136(8):1027-34. http://dx.doi.org/10.1017/ S095026880700951X PMid:17892633 PMCid:PMC2870901

7. Sistema Epidemiologico Integrato Epatiti Virali Acute (SEIEVA). Incidence of acute viral hepatitis (per 100,000) by age, sex and geographic area. SEIEVA 2010. Rome: Istituto Superiore di Sanità. Accessed [2 Jul 2013]. Available from: http://www.iss. it/binary/seie/cont/Incidence10.pdf

8. European Centre for Disease Prevention and Control (ECDC), European Food Safety Authority (EFSA). Outbreak of hepatitis A virus infection in residents and travellers to Italy. Stockholm: ECDC. 28 May 2013. Available from: http://ecdc.europa.eu/en/ publications/Publications/hepatitis-A-outbreak-of-hepatitis-Avirus-infection-in-residents-and-travellers-to-Italy.pdf

9. MacDonald E, Steens A, Stene-Johansen K, Gillesberg Lassen S, Midgley SE, Lawrence J, et al. Increase in hepatitis A in tourists from Denmark, England, Germany, the Netherlands, Norway and Sweden returning from Egypt, November 2012 to March 2013. Euro Surveill. 2013;18(17): pii=20468. Available from: http://www.eurosurveillance.org/ViewArticle. aspx?Articleld $=20468$ PMid:23647624

10. European Centre for Disease Prevention and Control (ECDC). Rapid risk assessment. Outbreak of hepatitis A virus infection in travellers returning from Egypt. Stockholm: ECDC. 30 Apr 2013. Available from: http://ecdc.europa.eu/en/publications/ Publications/RRA-Outbreak-hepatitis-A-virus-infectiontravellers-returning-from-Egypt.pdf

11. Dakic Z, Musa S. Hepatitis A outbreak in Bijeljina, Bosnia and Herzegovina, August 2012 - April 2013. Euro Surveill. 2013;18(21): pii=20486. Available from: http://www. eurosurveillance.org/ViewArticle. aspx?Articleld=20486 PMid:23725978

12. Gillesberg Lassen S, Soborg B, Midgley SE, Steens A, Vold L, Stene-Johansen K, et al. Ongoing multi-strain food-borne hepatitis A outbreak with frozen berries as suspected vehicle: four Nordic countries affected, October 2012 to April 2013. Euro Surveill. 2013;18(17):pii=20467. Available from: http:// www.eurosurveillance.org/ViewArticle.aspx?Articleld $=20467$

13. Centers for Disease Control and Prevention (CDC). Multistate outbreak of Hepatitis A infections potentially associated with "Townsend Farms Organic Antioxidant Blend" frozen berry and pomegranate mix. 3 Jul 2013. Atlanta: CDC. Available from: http://www.cdc.gov/hepatitis/Outbreaks/2013/A1b-03-31/

14. Heymann DL, editor. Control of Communicable Diseases Manual. 19th ed. Washington, D.C.: American Public Health Association; 2008. 